\title{
Architectural conservation of traditional mural paintings: the Sri Lankan experience
}

\author{
T.D. Nishantha Perera
}

\begin{abstract}
Architectural conservation provides necessary methodologies and skills to conserve traditional Sri Lankan mural paintings that are user objects in the ancient image houses. Most of these paintings are in dilapidated conditions due to natural decay and human intervention. Reduction of the rate of decay is the most important aspect of thier conservation.In this experimental study, we found that methods based on synthetic material that are currently used do not reduce the rate of decay of paintings, only those methods that stabilize the behavior of paintings reduce the rate of decay. It was established that methods based on traditional material could effectively stabilize the behavior of paintings. Based on these findings, appropriate methods of conservation are developed. Prime attention is given to filling, fixation and consolidation. The possibility of using cleaning and reintegration as tools of preservation is discussed.
\end{abstract}

\section{Introduction}

Traditional mural paintings in Sri Lanka are present in the image houses of ancient temples. Most of these temples are in regular use by the devotees. Images are the primary ritual objects in the image house. Mural paintings have a supplementary function to images. They intensify the effect of images and had been created to depict religious stories, often in a narrative style.

A large number of traditional mural paintings created from Anuradhapura to Southern period exist to date. Murals belonging to several painting schools (Bandaranayake, 1986) had been executed using several painting techniques (De Silva \& Perera, 2002a). Classical, Kandyan and Southern are the three major painting schools. Classical and Kandyan techniques are the two principal painting techniques adopted. Other techniques are closely related to one of them. Several architectural forms of image houses had been constructed in the island. Major architectural forms are cave based image houses of the Anuradhapura and the Kandyan periods; brick vaulted image houses of the Polonnaruva period; image houses on pillars of the Kandyan period, and masonry image houses of the Kandyan and the Southern periods. The origin and evolution of these image houses and arrangement of artifacts in them have been systematically studied (Silva, 1988: 210-275). The linear arrangement of spaces practiced during the classical period had developed to a circular arrangement during later times. Mural paintings within an image house follow a strictly defined hierarchical order. Most of these paintings are in a dilapidated condition, being subject to continuous decay as a result of exposure to environmental and human factors.
Conservation of traditional mural paintings is a fundamental need of heritage conservation. Architectural conservation provides necessary methodologies and skills for the active conservation of monuments that are in use (Cather, 1991). Reports published by the Department of Archaeology ( $\mathrm{De}$ Silva, 1964) and the Central Cultural Fund (Weerasinghe, 1987) and investigation of conservation done by these institutions indicate that conservation during the sixties had been mainly confined to cleaning and structural repair while cleaning, consolidation and fixation are being done at present. Such timely conservation action preserved a large number of paintings by maintaining their structural stability and preventing material loss. However, these conservation methods, primarily focused on the repair of defects and the enhancement of the visual quality of paintings, increased their rate of decay. Although these factors are primarily taken into account when conserving the user objects that have the function of creating visual perception and sensation, all interventions aimed at increasing the useful life of paintings must contribute to the minimization of decay. Direct usage of conservation methods developed for fresco paintings had brought about the destruction of our paintings due to the incompatibility in material and approach. For example, usage of synthetic polymers to fix and consolidate paintings has already caused severe destruction to many. paintings such as those at the Tivanka Image House, Polonnaruva. On the other hand, the beneficial features of usage of traditional material for conservation have been already pointed out (De Silva et $a l, 2002 a$ ). It is therefore necessary to identify the most appropriate strategies to preserve traditional mural paintings and develop relevant methodologies to implement them. 
Preservation, repair of defects and enhancement of user values are the main aspects of architectural conservation. Reduction of the rate of decay is the most vital necessity in preservation. Intervention is necessary to repair defects, to enhance user values and to improve stability for prevention of structural collapse. Architectural conservation needs to safeguard the authenticity of the monument and its patron/builder. All intervention should, ideally, be minimal. The adopted conservation strategies should relate to both application and user functions without conflict.

It has been long established that those monuments with stable environmental conditions were well preserved (Cronyn, 1990). The practical possibility of the adoption of a method based on this principle has not been studied. Analysis of Sri Lankan paintings that were subject to different environmental conditions proved that there is a high degree of bihavioural variation between them (De Silva \& Perera, 2002b). It was possible to determine that paintings in stable environmental conditions performed better than others. The strong relationship that exists between the behavior of paintings and the rate of decay has been systematically proved (De Silva et al, 2002b). This fact led to the assumption that intervention to stabilize the behavior of a mural painting in its environment could, in fact, preserve it. Physical defects present in paintings as a result of decay generated more intervention. A systematic investigation was necessary to determine the effectiveness of repair in stabilizing behavior and to determine whether such stabilization brings down the rate of decay to an acceptable level. This research was founded with the objective of developing such strategies.

\section{Methodology}

Two categories of samples were produced according to the Tivanka and Degaldoruva techniques to simulate structure and function of traditional paintings. Tivanka is a brick-vaulted image house in the citadel of Polonnaruva. It is the only site that accommodates some unfragmented Polonnaruva period paintings. Paintings that represent the peak of the Kandyan tradition exist in good condition at Degaldoruva rock temple situated close to Kandy. The Tivanka Technique was selected to model lime-based paintings, Degaldoruva models clay-based paintings. Sequential steps of production processes were determined by analyzing structure and composition of minute samples obtained from these sites and obtaining information from traditional technical (silpa) texts (Chakrabarti, 1980) and investigations done later (Coomaraswamy, 1956). Thirty samples were produced from each category. Cross sections of these samples were observed under the $20 \times 4$ magnification of the stereomicroscope. Thickness of layers was measured and particle sizes were determined using a graticular eyepiece and a stage graticule. Composition of layers of these paintings has already been identified (Agrawal \& Wickramasinghe, 2002).

Five samples were randomly selected from each category and the moisture absorption rate, moisture transmission rate, moisture evaporation rate and thermal movement of these samples were measured daily for two weeks to determine their behavior. Surface moisture level was measured using a Proti-meter Surveymaster. Thermal movement was measured under the microscope since the sensitivity of the extensometer was not enough. Rates of moisture absorption, moisture transmission and moisture evaporation were determined in accordance with differences in masses. It was necessary to generate defects in these samples in order to test repair interventions on them. Twenty samples were randomly selected from each category and they were subjected to destructive intervention. Cracking, fracturing and flaking of the paint layer were created by heating to 40 ${ }^{\circ} \mathrm{C}$ and cooling to $8{ }^{\circ} \mathrm{C}$, alternatively. Formation of lacunae was simulated by selective removal of paint layers by physical intervention. Fractures and cracks in the painting ground were generated by subjecting the samples of category one (Tivanka) to $100 \mathrm{~Pa}$ and category two (Degaldoruva) to $10 \mathrm{~Pa}$. Soot was deposited on three samples from each category by holding them over a bunsen flame. Another set of samples were introduced with $0.01 \mathrm{M} \mathrm{NaCl}$ and 0.01 $\mathrm{M} \mathrm{K}_{2} \mathrm{SO}_{4}$ and the salts allowed to deposit on the surface.

Samples were placed in $27{ }^{\circ} \mathrm{C}$ and $75 \%$ relative humidity and they were supplied with a constant amount of moisture through their support. $10 \mathrm{~mL}$ of moisture was introduced to category one samples; it was $6 \mathrm{~mL}$ for category two. Moisture transmission rate, moisture evaporation rate and thermal movement of these samples with defects were measured again for two weeks. They were then subjected to repair interventions as described below and listed in Table 1. 
Table 1: Interventions made to samples

\begin{tabular}{|c|l|c|l|l|l|}
\hline & Samples & Category & $\begin{array}{l}\text { Destructive } \\
\text { Intervention }\end{array}$ & Effect & $\begin{array}{l}\text { Repair } \\
\text { intervention }\end{array}$ \\
\hline 1 & T1-5 & 1 & Heating and cooling & $\begin{array}{l}\text { Cracking of paint, } \\
\text { flaking }\end{array}$ & Acrylic resin \\
\hline 2 & T6-10 & 1 & Heating and cooling & $\begin{array}{l}\text { Cracking of paint, } \\
\text { flaking }\end{array}$ & Lime \\
\hline 3 & D1-5 & 2 & Heating and cooling & $\begin{array}{l}\text { Cracking of paint, } \\
\text { flakina }\end{array}$ & Acrlic resin \\
\hline 4 & D6-10 & 2 & Heating and cooling & $\begin{array}{l}\text { Cracking of paint, } \\
\text { flaking }\end{array}$ & Gum \\
\hline 5 & T11-15 & 1 & Physical intervention & Lacunae & Acrylic resin \\
\hline 6 & T16-20 & 1 & Physical intervention & Lacunae & Clay-lime \\
\hline 7 & D11-15 & 2 & Physical intervention & Lacunae & Acrylic resin \\
\hline 8 & D16-20 & 2 & Physical intervention & Lacunae & Clay-gum \\
\hline 9 & T21-25 & 1 & Mechanical force & Fractures in ground & Acrylic resin \\
\hline 10 & T26-30 & 1 & Mechanical force & Fractures in ground & Lime-gum \\
\hline 11 & D21-25 & 2 & Mechanical force & Fractures in ground & Acrylic resin \\
\hline 12 & D26-30 & 2 & Mechanical force & Fractures in ground & Clay-gum \\
\hline
\end{tabular}

2.1 Lacunae of paint: Two kinds of interventions were done to each category of samples. For five category one samples; $1 \%$ of acrylic resin dissolved in distilled water was used to fill lacunae of paint present in $50 \%$ of painted surface. $\mathrm{CaO}$ and $\mathbf{3 0 0}$ mm clay, mixed in 1:4 proportion, were used with a suitable amount of water to fill the second set of five samples. The first intervention was given to five samples of category two also. Clay and wood-apple gum mixture with an applicable consistency was used for the second set of five samples. Care was taken to limit thickness of filler to $2 \mathrm{~mm}$.

2.2 Lacunae of ground: The above intervention was done making the filling 5-8 $\mathrm{mm}$ thick.

2.3 Flaking: Same material used in filling was used as the fixative. $0.5 \%$ acrylic resin was used. Lime and gum concentrations were increased in respective mixtures.

2.4 Cracks and fractures of paint:Three samples with defects from each category were applied with a coat of acrylic resin on the surface. Limewater was used on another set of category one samples and wood-apple gum was used for category two.

2.5 Cracks and fractures in ground; $3 \%$ acrylic resin was used to repair cracks and fractures of five sets of samples from each of the two categories. Five samples from each of these categories were repaired using lime putty and clay-wood-apple gum mixture respectively. A high amount of gum was used for this intervention.
2.6 Cleaning: Cleaning of soot and salt was done after observation of the surface with a simple microscope. Mechanical cleaning was the principal method used. Water was used when salts remained on the surface after mechanical cleaning and xylene or alcohol was used only where necessary.

2.7 Reintegration: Watercolor was used for reintegration of lacunae. Paint was applied in different thicknesses over varying surface areas of filled lacunae.

\section{Results and Analysis}

The following recipes could be reformulated by analyzing the paintings.

3.1 Tivanka Technique: Obtain clear sand from a clean place and sieve using mesh size of $600 \mathrm{~mm}$. Use finely powdered pale brown clay of $230 \mathrm{~mm}$ average particle size. Mix clay and sand in 3:2 proportion. Finely powder pure white dolomatic lime that contains $\mathrm{CaCO}_{3}$ and $\mathrm{MgCO}_{3}$ in 2:1 proportion. Mix lime and clay-sand in 3:2 proportion and add an adequate amount of water. Wash the support with pure water and then with limewater. Smear the wall with lime plaster. Average thickness of the layer should be $2 \mathrm{~cm}$. Thickness may vary in each location to counteract the uneven nature of support. Allow it to dry. Prepare a second mixture using lime and sand mixed in 3:2 proportion. Lay $1 \mathrm{~cm}$ thick layer over the dried first layer. Use very finely powdered lime for the paint-receiving layer. Smear a thin layer of lime over the hardened smooth surface of ground. The surface should be pure white and totally smooth after hardening. 
It must be absolutely devoid of any irregularities and deformations: Use red-ochre, yellow ochre and terreverte as red, yellow and green pigments respectively. Finely powder each of them and mix with an adequate amount of wood-apple gum. Use lamp black as the black paint. Follow steps listed below for drawing:

1. sketch the drawing with a pencil

2. complete the line drawing with a brush using red paint

3. apply colors

4. complete coloring with shading and tonal variations

5. make the final outlines using black color

6. finalize with finishing touches

3.2 Degaldoruva Technique: Mix fine brown clay of 240 $\mathrm{mm}$ particle size and $500 \mathrm{~mm}$ sand in 2:1 proportion. Add wood-apple gum dissolved in hot water and cotton fiber to it. Add a low proportion of rock grit. Add an adequate proportion of water. Lay the mixture on the brick support to $2.5 \mathrm{~cm}$ thickness. Allow it to dry ensuring a smooth uniform layer after drying. Use huntite as the paint-receiving layer. Smear a thin layer of it on the dry painting ground. Its thickness should not be more than $1 \mathrm{~mm}$. It must have pure white color after drying. Finely powder cinnabar, orpiment and lead white pigments.Mix with wood-apple (Limonia acidissima) gum to an adequate viscosity. Prepare indigo pigment by beating indigo (Indigofera tincloria) leaves in water and allowing fermentation. Powder the pigment and mix with wood-apple gum. Prepare black paint by mixing lamp black with wood-apple gum. Drawing should be done according to following order.

1. apply cinnabar on the drawing area of the wall to have uniform color and even thickness

2. draw the painting after drying

3. paint with white, yellow and black colors

4. reinforce the line using black paint

5. write the topics in black

Samples produced using these recipes remained stable without showing signs of decay for six months. Cracking and fracturing could be generated within two months by changing temperature and subjecting the samples to mechanical stress.

3.3 Lacunae were formed after four months. Areas of paint could be removed by applying $0.1 \mathrm{~N}$ force to cleave layers.Lime painting samples were stronger than the clay samples and needed $100 \mathrm{~Pa}$ to create structural defects.

Table 2: Parameters of behavior (average amounts): normal and deteriorated samples

\begin{tabular}{|l|l|c|c|c|c|}
\hline & \multicolumn{1}{|c|}{ Parameter } & $\begin{array}{c}\text { Category one } \\
\text { (normal) }\end{array}$ & $\begin{array}{c}\text { Category one } \\
\text { (with defects) }\end{array}$ & $\begin{array}{c}\text { Category two } \\
\text { (normal) }\end{array}$ & $\begin{array}{c}\text { Category two } \\
\text { (with defects) }\end{array}$ \\
\hline 1 & $\begin{array}{l}\text { Moisture absorption rate } \\
\text { (mLday) }\end{array}$ & 8.2 & 8.3 & 4.2 & 4.1 \\
\hline 2 & $\begin{array}{l}\text { Moisture transmission rate } \\
\text { (mLday) }\end{array}$ & 6.3 & $3.8-5.7$ & 3.9 & $1.3-3.8$ \\
\hline 3 & $\begin{array}{l}\text { Moisture evaporation rate } \\
\text { (mLday) }\end{array}$ & 5.8 & $1.8-5.1$ & 3.7 & $0.8-3.3$ \\
\hline 4 & Thermal movemeat (\%) & 3.9 & $12.4-14.6$ & 4.7 & $6.9-14.2$ \\
\hline
\end{tabular}

Table 3: Amount of change in behavior after repair

\begin{tabular}{|l|l|l|c|c|c|}
\hline & Parameter & $\begin{array}{c}\text { Category one } \\
\text { (synthetic) }\end{array}$ & $\begin{array}{c}\text { Category one } \\
\text { (traditional) }\end{array}$ & $\begin{array}{c}\text { Category two } \\
\text { (synthetic) }\end{array}$ & $\begin{array}{c}\text { Category two } \\
\text { (traditional) }\end{array}$ \\
\hline 1. & $\begin{array}{l}\text { Moisture absorption rate } \\
(\% \text { change) }\end{array}$ & -5.0 & -0.1 & -0.8 & 1.1 \\
\hline 2. & $\begin{array}{l}\text { Moisture transmission rate } \\
\text { (\% change) }\end{array}$ & -99.0 & -11.2 & -98.8 & -8.2 \\
\hline 3. & $\begin{array}{l}\text { Moisture evaporation rate } \\
\text { (\% change) }\end{array}$ & -99.8 & 1.2 & -97.4 & 4.4 \\
\hline 4. & $\begin{array}{l}\text { Thermal movement } \\
\text { (\% change) }\end{array}$ & -44.9 & 0.2 & -22.7 & 0.9 \\
\hline
\end{tabular}




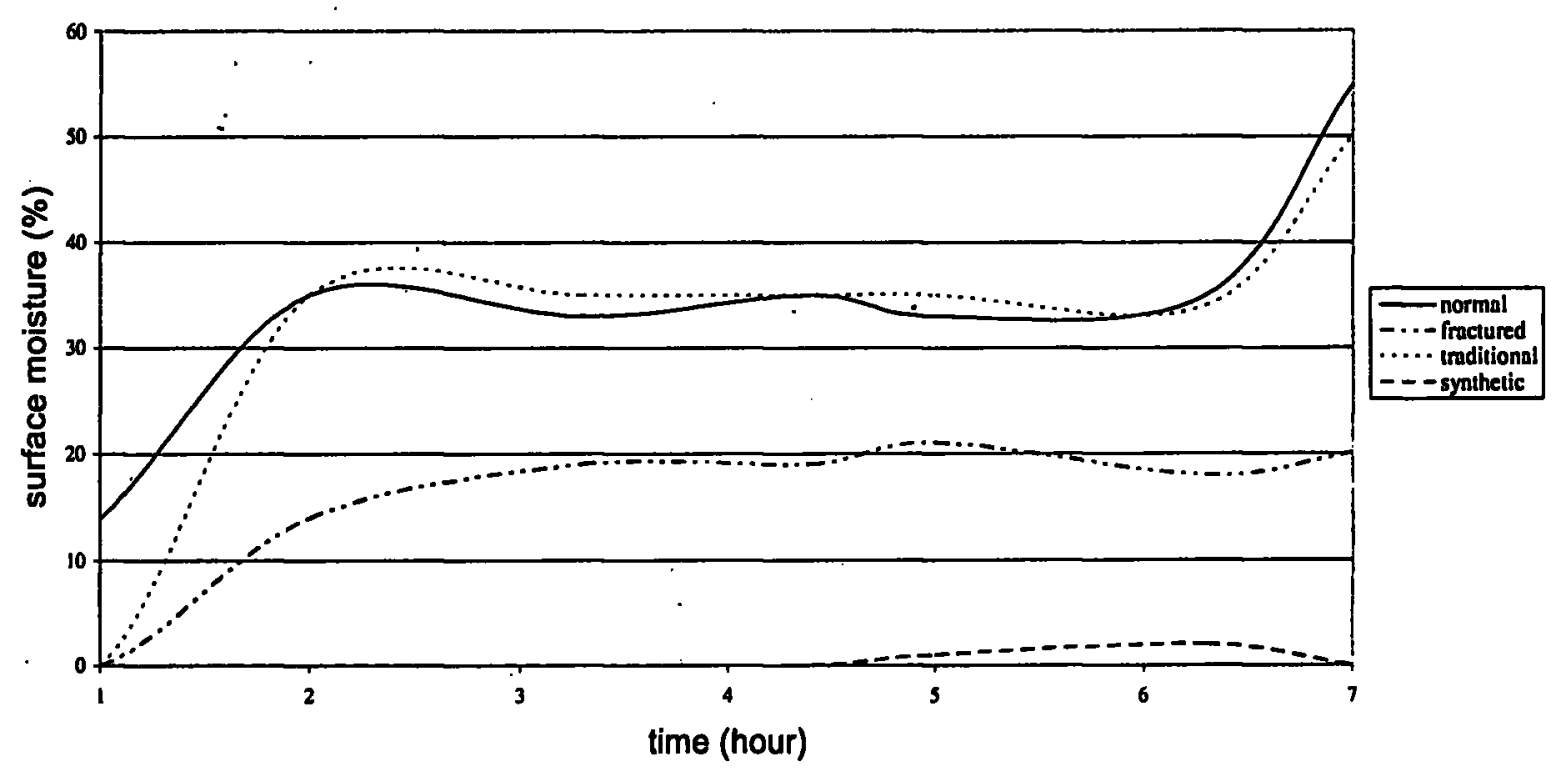

Fig 1: Molsture transmission of samples

Average moisture absorption rate, moisture transmission rate, moisture evaporation rate and thermal movement of these samples are listed in table 2 with the appropriate levels of these parameters. Appropriate levels were determined according to the normal levels of parameters measured before creation of defects. Amount of change in behavior of samples repaired with synthetic and traditional materials is listed in Table 3. Interventions done with synthetic resins repaired the defects in the appropriate structural quality. However, these interventions were totally unacceptable due to high attenuation of moisture movement by them (figure 1). It is therefore emphasized that the usage of synthetic polymers to repair defects brings about decay of paintings. It was understood that traditional materials could repair the structural defects adequately only under the correct composition (figure 2). The intervention could improve the behavior towards the required level. Composition had to be changed to attain the required properties of moisture behavior.

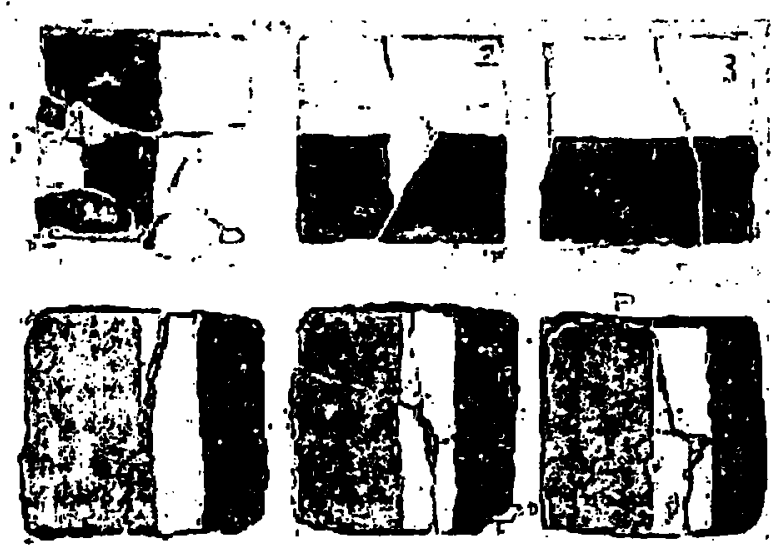

Fig 2: Samples subjected to repair intervention

The samples repaired with traditional material remained stable without showing color alterations or formation of defects for eighteen months. According to this observation, their rate of decay was low. It was therefore emphasized that repair interventions based on traditional materials is an effective method of reducing the rate of decay of traditional mural paintings.

\section{Discussion}

This investigation has established that repair interventions carried out with traditional material could bring about normal behavior of mural paintings. Rate of decay of such paintings remained low. Synthetic material cannot be used in conservation until such time as their qualities will be improved to suit behavior of traditional paintings.

\subsection{The process of architectural conservation}

According to the results obtained from the above investigation, it was emphasized that the repair interventions based on traditional material aimed at stabilization of behavior is the best strategy that could be adopted to preserve traditional mural paintings. Further testing was done to determine the suitable methods for its practical adoption. The following procedure of conservation was developed from this study:

1. Investigations necessary prior to intervention: Nature of defects and the condition of the painting must be analyzed prior to making intervention. Behavior of the painting with defects has to be determined by relevant measurements. These parameters may be estimated (Table 1) if measurement is practically impossible. Required moisture behavior should be determined according to the technique and present status of the painting. Amount and type of intervention and material used must be planned according to this requirement. It is planned to use a basic mixture for each of clay and lime based paintings. Proportion of constituents of this mixture may vary according to the individual requirement. 
Basic mixture recommended for use on lime-based paintings is pure $\mathrm{CaO}$ and clay in 1:4 proportion. $\mathrm{A}$ suitable amount of deionized water should be added to produce hydroxide and get the mixture into workable consistency. Proportion of clay should be increased when higher amounts of evaporation are necessary. Limewater is the fixative proposed for these paintings. Saturated limewater should be used. Plant gum may be used if higher levels of adhesion are necessary. Clay-gum is the recommended mixture for consolidation of clay-based paintings. Gum-water should be used for fixation.

\section{Fixation of the paint layer:}

Repeated application of limewater fixes the paint layer of lime based paintings adequately. Gum-water should be used on the clay-based paintings. Solutions of gum are prepared by dissolving the solid in hot water. It must be noted that higher concentrations of wood-apple gum make the surface glassy. Wood-apple gum is nonvolatile. Surface absorption is also low. A film will be formed on the surface. Its thickness will depend on the concentration and frequency of application of gum. Glassy film tends to crack. Higher concentrations must therefore be avoided.

\section{Filling of lacunae of lime - based paintings:}

Final composition of the filler and required thickness of the layer should be in accordance with the required behavior. Gum Arabic may be used to increase the adhesion of fixative. Wood-apple gum should be used if higher levels of adhesion are necessary. Since these gums, especially wood-apple gum, severely attenuate moisture transmission, they should not be applied on the larger areas of the surface.

4. Filling of clay paintings: Particle size of clay should be selected according to the required rate of evaporation. Clay of particle sizes varying from 200 to $400 \mathrm{~mm}$ may be used. Concentration of gum depends on the relevant rate of evaporation and the degree of adhesion necessary. Diluted gum arabic is used to obtain low levels of adhesion. High concentrations of wood-apple gum increase adhesion but with a loss of evaporation.

5. Fixation of flaked and weakened surface layers: Fixation provides room for the control of surface evaporation. Limewater, with the addition of gum if necessary, is suited for lime based paintings. Gum arabic or wood-apple gum should be used as the fixative for clay based paintings.

Higher concentrations of gum may be used to limit evaporation. Frequency of application may be increased to gain higher levels of adhesion that may be necessary.

6. Consolidation of internal voids: Same basic mixtures used for filling may be used to consolidate internal voids. Moisture transmission is the primary factor that needs to be considered. Paintings having internal voids have impaired moisture transmission rates. A proper consolidation will revert it back to its normal rate.

7. Preservative cleaning: Cleaning becomes an act of preservation when it removes harmful deposits and/or stabilizes the behavior of the painting. Harmful deposits like salts must be removed from the painting. Mechanical removal is recommended. Cleaning must be done without damaging the paint layer and patina. Care is necessary not to disturb paint layers fixed by the natural actions. Degree of cleaning is determined according to the required behavior of the painting. It must be emphasized that deposits are an archaeological layer that reveals natural actions may have occurred on the painting, sequential changes of the environment and types of interventions done in the past. Inadvertent removal of deposits is an act of destruction of valuable archaeological data. Removal of preservative deposits, damage to patina and exposure of the paint layer to harmful environment are also acts of destruction. Preliminary fixation of flaked layers may be done before cleaning. Hard encrustations are not normally present and removal of them by solvents should be attempted only when necessary. Deionized water is preferred and every attempt must be taken to limit solvents to water or very dilute solutions. Degree of cleaning must be decided according to the amount of evaporation necessary. Removal of soot should be done to an extent to promote the amount of evaporation needed. No attempt must be taken to remove soot or oily dust deposited on an over-drying painting. Cleaning often damages patina and disturbs preserved areas. A compromise is therefore necessary in between the removal of harmful deposits, required level of evaporation and protection of preserved areas.

8. Cleaning of internal pores: This is possible only when migrating moisture dissolves internal crystallizations, carries and deposits them on the surface. Moist cotton swabs may be used to remove surface deposits.

9. Preservative reintegration: Reintegration should be done to control moisture evaporation and prevent harmful deposits contacting the paint layer. Paint may be applied to act as a sacrificial layer that may be replaced from time to time. Watercolors that do not contain harmful dyes must be used for reintegration. They may have a limited lifetime.

\subsection{Recommendations}

The recommended conservation process for paintings exposed to different conditions is briefly described below.

1. Paintings in over-drying condition: This is the typical condition of most Sri Lankan paintings. These paintings gain very little amount of moisture through their support, 
often very much lower than that required to maintain cohesion. Periodical application of gum on the surface is recommended.

2. Damp paintings: After cutting off links of moisture absorption, painting must be allowed to dry under nomal conditions. Dehumidification of internal air, and increase of temperature, not more than $5^{\circ} \mathrm{C}$, may be done if possible. Cleaning may be done to increase the rate of evaporation through surface if surface layers remain intact. Application of any other substance on the surface for fixation, consolidation or reintegration must not be done until internal dampness will be totally eliminated.

3. Reconstruction of a fragmented painting: Fragments and cleaved parts may be fixed using mixtures of traditional material. The painting can be restored to its previous state if uniformity of fragments and interfaces can be maintained. Such an intervention protects the authenticity of the structure and material of the painting and its creator.

Prime attention was paid in this investigation to preserve mural paintings by reducing their rate of decay. Defects provided room to carry out relevant intervention. Suitable intervention stabilized behavior of mural paintings and reduced their rate of decay to an unavoidable minimum. Such an approach will preserve traditional mural paintings in their maximum useful lifetime.

\section{Acknowledgement}

The material presented in this research paper is based on research done by the author at the Department of Architecture, University of Moratuwa for a PhD degree in painting conservation. Supervision by Prof. T.K. Nimal P. De Silva, Archt. C.J. de Saram and Dr. M.S. Manawadu and financial assistance provided by the Senate Research Committee of the University of Moratuwa (Research Grant No. SRC/2000/02/06) are gratefully acknowledged.

\section{References}

Agrawal, O.P. and Wickramasinghe, N.A. (2002), "Materials and techniques of ancient wall paintings of Sri Lanka", Lucknow: INTACH.

Bandaranayake, S. (1986), "The rock and wall paintings of Sri Lanka", Colombo: Lake House.
Cather, S. ed (1991), "The conservation of wall paintings", London: Getty Foundation.

Chakrabartl, J. (1980), "Techniques in Indian mural painting", Calcutta: K.P. Bagchi.

Coomaraswamy, A.K. (1956), "Madieval Sinhalese Art", second edition,New York, NY: Pantheon.

Cronyn, J.M. (1990), "The elements of archaeological conservation", London: Roulledge.

de Silva, R.H. (1964-1968), "Chemical treatment of antiquities" in ASCAR.

De Silva, T.K.N.P. and Perera, T.D.N. (2002a), “The identification of traditional Sri Lankan painting techniques" in SLAAS Proceedings of the fifty eighth annual session, Part One: Abstracts p. 94

De SIlva, T.K.N.P. and Perera, T.D.N. (2002b), "The investigation of behavior patterns in traditional Sri Lankan mural paintings" in SLAAS Proceedings of the fifty eighth annual session, Part One: Abstracts p. 95.

De Silva, T.K.N.P.; Perera, T.D.N. and de Mel, V.P.A. (2002a), "An investigation of the usage of traditional material to preserve traditional Sri Lankan mural paintings" in SLAAS Proce日dings of the fifty eighth annual session, Part One: Abstracts p. 93.

De Sllva, T.K.N.P.; Perera, T.D.N. and Weerasooriya, S.G. (2002b), "A simulated study on the correlation between stable behavior and the rate of decay in traditional Sri Lankan mural paintings" in SLAAS Proceedings of the fifty eighth annual session, Part One: Abstracts p. 92.

Silva, R. (1988), "Religious architecture in early and medieval Sri Lanka", Druk: Krips Repro Meppel.

Weerasinghe, J. (1987), "Conservation of mural paintings and polychrome objects - the progress report", Colombo: CCF. 